\title{
Editorial
}

Respiration 2006;73:147-148

DOI: $10.1159 / 000091531$

\section{Noninvasive Ventilation in Acute Pancreatitis Respiratory Failure: Deus ex Machina?}

\author{
Ioannis Pneumatikos ${ }^{a}$ Demosthenes Bouros ${ }^{b}$ \\ ${ }^{a}$ Intensive Care Unit, and ${ }^{b}$ Department of Pneumonology, Medical School, Democritus University of Thrace, \\ Alexandroupolis, Greece
}

Thirty years ago, the mortality of acute pancreatitis has fallen from 25 to $30 \%$, but remained at $6-10 \%$ for most of the past 2 decades [1]. The initial improvement did not occur because of any specific treatment for acute pancreatitis, but because of improved supportive treatment especially due to advances in critical care. In a recent study, acute respiratory failure (ARF) was among the five independent prognostic factors for hospital mortality in severe acute pancreatitis (the patient's age, chronic health situation, and organ failures, i.e. respiratory, renal, and cardiovascular) [2]. Since $60 \%$ of deaths from acute pancreatitis occur within the first week of illness and have been associated with ARF, much attention has been drawn to the treatment of pulmonary complications, such as pleural effusion, atelectasis, pneumonia, and acute lung injury or acute respiratory distress syndrome [3].

Noninvasive positive pressure ventilation (NPPV) constitutes a therapeutic advance for certain forms of respiratory failure. NPPV is used in ARF with the aim of decreasing the work of breathing and improving gas exchange. Current evidence supports the use of NPPV to avoid endotracheal intubation and its attendant morbidity and mortality in selected patients caused by chronic obstructive pulmonary disease exacerbations or immunocompromized states $[4,5]$. Although NPPV is commonly used to treat acute pulmonary edema, data support the use of continuous positive airway pressure alone for this entity [6]. However, the use of NPPV for other shortterm applications, such as postoperative respiratory failure, as a means of facilitating weaning from mechanical ventilation or preventing extubation failure, is recommended [7]. NPPV has also been used to treat numerous other causes of ARF, but controlled studies to support these applications are lacking [8].

In this issue of Respiration, Jaber et al. [9] conducted a study aimed to evaluate their clinical experience with NPPV in the treatment of acute pancreatitis patients with ARF. Although this is a retrospective observational study, its value is distinct because it is the first study in the literature which reports on the potential efficacy of NPPV in acute pancreatitis patients with ARF. In this study, 15 (54\%) of the 28 patients treated with NPPV were not intubated and, as a consequence, had a significantly shorter intensive care unit stay. The more interesting finding is that the failure of NPPV did not depend on the severity of illness or physiologic parameters of gas exchange, but on the presence of bilateral alveolar infiltrates, atelectasis, and abdominal distention. These data emphasize that ARF in patients with acute pancreatitis is a combination of lung disorders (diffuse damage and collapse of alveoli due to acute lung injury/acute respiratory distress syndrome) and a restrictive ventilatory defect due mainly to a cephalad shift of the diaphragm secondary to ascites. Moreover, impairment of diaphragmatic strength and en-

\section{KARGER}

Fax +4161306 1234 E-Mail karger@karger.ch www.karger.com
(C) 2006 S. Karger AG, Basel

0025-7931/06/0732-0147\$23.50/0

Accessible online at: www.karger.com/res
Demosthenes Bouros, MD, PhD, FCCP

Department of Pneumonology

Medical School University of Thrace

GR-68100 Alexandroupolis (Greece)

Tel. +3021060 01213, Fax +30 25510 76106, E-Mail bouros@med.duth.gr 
durance capacity may contribute to this ventilatory dysfunction [10]. Despite the theoretical advantage of NPPV, i.e. recruitment of zones of alveolar collapse and minimizing the work of breathing, its routine use in such situations could not be advised, especially in acute pancreatitis patients with multiorgan system failure who are likely to require prolonged ventilatory support using sophisticated ventilator modes. However, the early use of NPPV in mild cases of ARF in acute pancreatitis patients should be encouraged as a prophylactic mean because positive end-expiratory pressure prevents alveolar col- lapse and may improve oxygenation by increasing mean airway pressure and functional residual capacity.

In conclusion, the study of Jaber et al. [9] could be the basis for future prospective randomized studies comparing the use of NPPV with conventional ventilatory support in acute pancreatitis patients with ARF. If such a trial is initiated, patients should be closely monitored and promptly intubated if their condition deteriorates, so that unjustified delays in necessary interventions are avoided.

\section{References}

1 Neoptolemos JP, Raraty M, Finch M, Sutton $\mathrm{R}$ : Acute pancreatitis: the substantial human and financial cost. Gut 1998;42:886-891.

2 Halonen KI, Leppaniemi AK, Puolakkainen PA, et al: Severe acute pancreatitis: prognostic factors in 270 consecutive patients. Pancreas 2000;21:266-271.

3 Renner IG, Savage WT 3rd, Pantoja JL, Renner VJ: Death due to acute pancreatitis: a retrospective analysis of 405 autopsy cases. Dig Dis Sci 1985;30:1005-1018.

4 Brochard L, Mancebo J, Wysocki M, et al: Noninvasive ventilation for acute exacerbations of chronic obstructive pulmonary disease. N Engl J Med 1995;333:817-822.
5 Hilbert G, Gruson D, Vargas F, et al: Noninvasive ventilation in immunosupressed patients with pulmonary infiltrates, fever and acute respiratory failure. N Engl J Med 2001; 344:481-487.

6 Bersten AD, Holt AW, Veding AE, et al: Treatment of severe cardiogenic pulmonary edema with continuous positive airway pressure delivered by face mask. N Engl J Med 1991;325: 1825-1830.

7 Liesching T, Kwok H, Hill N: Acute applications of non-invasive positive pressure ventilation. Chest 2003;124:699-713.
8 Rocker GM, Mackenzie MG, Williams B, et al: Noninvasive positive pressure ventilation: successful outcome in patients with acute lung injury/ARDS. Chest 1999;115:173-177.

9 Jaber S, Chanques G, Sebbane M, Salhi F, Delay J-M, Perrigault P-F, Eledjam J-J: Noninvasive positive pressure ventilation in patients with respiratory failure due to severe acute pancreatitis. Respiration 2006;73:166-172.

10 Matuszczak Y, Viires N, Allamedin H, et al: Alteration in diaphragmatic function induced by acute necrotizing pancreatitis in a rodent model. Am J Respir Crit Care Med 1999; 160: 1623-1628. 